\title{
Gene transfer of human prostacyclin synthase into the liver is effective for the treatment of pulmonary hypertension in rats
}

Hitoshi Suhara, MDa

Yoshiki Sawa, MDa

Norihide Fukushima, MD

Koji Kagisaki, MDa

Chieko Yokoyama, $\mathrm{PhD}^{\mathrm{b}}$

Tadashi Tanabe, $\mathrm{PhD}^{\mathrm{b}}$

Shigeaki Ohtake, $M D^{\mathrm{a}}$

Hikaru Matsuda, MDa

From the Division of Cardiovascular Surgery, Department of Surgery, Osaka University Graduate School of Medicine, ${ }^{\mathrm{a}}$ and the Department of Pharmacology, The National Cardiovascular Center Research Institute, ${ }^{\mathrm{b}}$ Osaka, Japan.

Read at the Eighty-first Annual Meeting of The American Association for Thoracic Surgery, San Diego, Calif, May 6-9, 2001.

Received for publication May 29, 2001; revisions requested July 13, 2001; accepted for publication July 13, 2001.

Address for reprints: Yoshiki Sawa, MD, Division of Cardiovascular Surgery, Department of Surgery, Osaka University Graduate School of Medicine, 2-2 Yamadaoka, Suita, Osaka 565-0871, Japan (E-mail: sawa@surg1.med.osaka-u.ac.jp).

J Thorac Cardiovasc Surg 2002;123:855-61

Copyright $\odot 2002$ by The American Association for Thoracic Surgery

0022-5223/2002 \$35.00+0 $\quad \mathbf{1 2 / 6 / 1 1 8 6 8 7}$ doi:10.1067/mtc.2002.118687
Background: As one of the future strategies of advanced pulmonary hypertension, intrinsic prostacyclin drug delivery using gene therapy may be useful. We investigated whether transfer of the prostacyclin synthase gene into the liver could ameliorate monocrotaline-induced pulmonary hypertension in rats.

Methods: The human prostacyclin synthase gene was transfected into the liver of rats with monocrotaline-induced pulmonary hypertension. Hemodynamic indices, blood samples, lung tissues, and survival curves were evaluated between rats receiving the gene and control rats.

Results: High levels of prostacyclin synthase gene expression were found in the hepatocytes of the prostacyclin synthase group. The level of 6-keto-prostaglandin $\mathrm{F}_{1 \alpha}$ was significantly higher in the prostacyclin synthase group (prostacyclin synthase, $35.4 \pm 4.4 \mathrm{ng} / \mathrm{mL}$; control, $22.3 \pm 3.3 \mathrm{ng} / \mathrm{mL} ; P=.0436$ ). The right ventricular/femoral artery pressure ratio was significantly lower in the prostacyclin synthase group than in the control group (prostacyclin synthase, $0.60 \pm 0.039$; control, $0.88 \pm 0.051 ; P=.0036)$. The endothelin-1 levels in the lung tissues were significantly lower in the prostacyclin synthase group than in the control group (prostacyclin synthase, $10.42 \pm 2.01 \mathrm{pg} / \mathrm{mg}$ protein; control, $19.94 \pm 2.82 \mathrm{pg} / \mathrm{mg}$ protein; $P=.0176)$. The survival ratio was significantly higher in the prostacyclin synthase group than the control group $(P=.0375)$.

Conclusion: This drug delivery system using gene transfer can be considered as an alternative for continuous intravenous prostacyclin infusion for pulmonary hypertension.

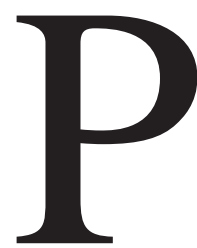

rimary pulmonary hypertension is a life-threatening disease characterized by progressive pulmonary hypertension and right ventricular failure, resulting in death. To date, there is no lifesaving treatment without lung transplantation. Recently, the intravenous administration of prostacyclin, a short-acting vasodilator, was shown to improve the hemodynamics and symptoms of patients with primary or secondary pulmonary hypertension associated with congenital heart defects. ${ }^{1-4}$ However, it is difficult to maintain a continuous intravenous administration of this drug over the long term, especially in children, because of clinical problems such as vessel access, infections, and low quality of life. Thus, the availability of alternative strategies, including gene therapy, would be beneficial for patients with critical pulmonary hypertension. 


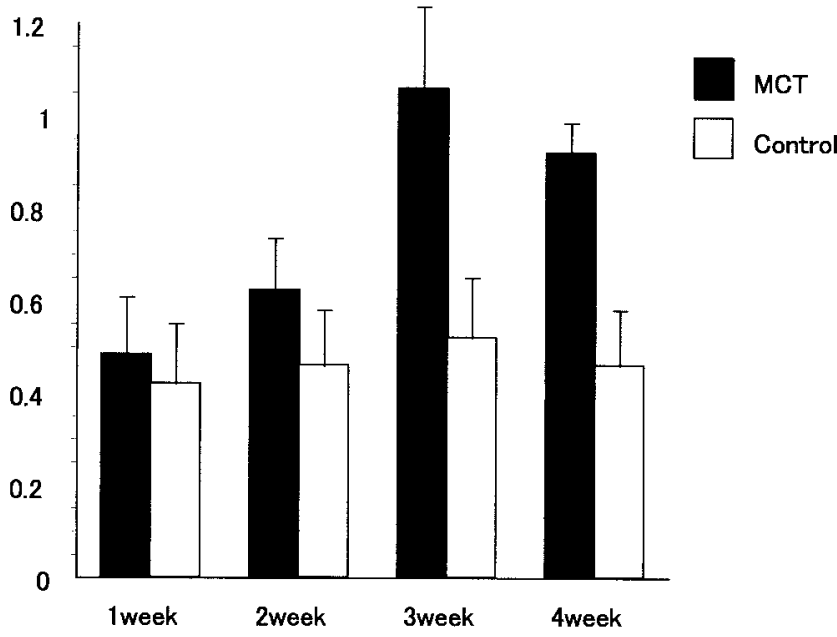

Figure 1. The RV/FA pressure ratios after MCT injection were shown. Black columns are the MCT group, and the white columns are the control group, which received only injections of saline solution. RV/FA pressure ratios were measured every week in 3 rats from each group. From 3 to 4 weeks after MCT injection, the right ventricular pressure equaled the systemic pressure.

Prostacyclin synthase (PGIS) catalyzes the conversion of prostaglandin $\mathrm{H}_{2}$ to prostacyclin. ${ }^{5}$ Recently, we determined the amino acid sequence of bovine and human endothelial PGIS by complementary DNA cloning6-9 and showed that transfection of the human PGIS gene could increase the amount of prostacyclin production in rats. ${ }^{10}$ Therefore, the transfection of the human PGIS gene might provide a novel therapy for treating pulmonary hypertension, effectively acting as a strong vasodilator and promoter of pulmonary regeneration. ${ }^{11}$

Several methods of gene transfection to the lungs have been reported, but these methods have limitations and are still controversial. ${ }^{11}$ However, the liver is a suitable organ for gene transfection for the delivery of endocrine factors to the lung. ${ }^{12-14}$ Therefore, because prostacyclin produced by PGIS functions as an endocrine agent, we hypothesized that the overexpression of PGIS in the liver might ameliorate pulmonary hypertension by delivering prostacyclin to the lungs.

In this study, we investigated whether transfection of the PGIS gene to the liver results in prostacyclin delivery to the lungs and whether this may be an effective treatment for pulmonary hypertension induced by monocrotaline (MCT) in rats.

\section{Materials and Methods}

\section{Pulmonary Hypertension Model}

Male Sprague-Dawley rats weighing approximately $200 \mathrm{~g}$ (Nihon Animal, Osaka, Japan) were used. Pulmonary hypertension was induced in the rats by a subcutaneous injection of MCT $(60 \mathrm{mg} / \mathrm{kg})$ in the neck. After MCT injection, we confirmed that the right ventricular systolic pressure rose gradually and reached the systolic pressure at the third week. The ratio of right ventricular to femoral arterial pressure (RV/FA) increased over time. Four weeks after the MCT injection, the right ventricular pressure appeared to show a slight decrease, but the difference was not significant (Figure 1). We used rats in the fourth week after MCT injection in this study.

\section{Experimental Protocols}

Gene transfection. Twenty rats with induced pulmonary hypertension were divided into the PGIS and control groups. An additional 10 rats were added to each group for the analysis of cumulative survival ratios. After the rats were anesthetized by an intraperitoneal injection of pentobarbital $(30 \mathrm{mg} / \mathrm{kg})$, a small peritoneotomy of the upper abdomen was performed, exposing the liver. Via a 27-gauge needle, $1 \mathrm{~mL}$ of a hemagglutinating virus of Japan (HVJ)-liposome complex that included $75 \mu \mathrm{g}$ of plasmid DNA was then injected into the liver.

Evaluation of hemodynamics after gene transfection. Hemodynamics was evaluated 7 days after gene transfer. After the rats were anesthetized by an intraperitoneal injection of pentobarbital, tracheal intubation was performed with a polyethylene catheter, and the intubation catheter was connected to a volume-regulated respirator (Shinano model SN480-7; Shinano Mainichi Shimbun Inc, Nagano, Japan) for mechanical ventilation $\left(\mathrm{FIO}_{2} 0.21\right.$, rate 60 breaths/min). For measurement of the systemic arterial pressure, a 24-gauge Angiocath catheter (Becton Dickinson, Franklin Lakes, $\mathrm{NJ})$ was inserted into the left femoral artery, and the arterial line was connected to a pressure transducer and polygraph. After median sternotomy, a 26-gauge needle connected to a pressure line was inserted into the right ventricle. The femoral arterial and right ventricular pressures were recorded at the same time and the RV/FA pressure ratio was calculated. After blood samples were removed, the rat was killed by pentobarbital overdose, and the liver, lungs, and heart were removed for histologic and protein assays. The experimental protocols were approved by the animal research committee of Osaka University Medical School.

\section{Construction of Plasmid DNA}

The expression vector for human PGIS was kindly provided by Dr Tanabe (Department of Pharmacology, National Cardiovascular Center). This plasmid was constructed by inserting the blunted Hind III/Bam HI fragment of the full-length human PGIS cDNA into the blunted Xho I site of the pUC/CAGGS expression plasmid. ${ }^{7}$

\section{Preparation of HVJ Liposomes}

The HVJ liposomes were prepared as described previously. ${ }^{15}$ In brief, $10 \mathrm{mg}$ of lipid mixture (phosphatidylcholine:dioleoylphosphatidyl ethanolamine:shingomyeline:cholesterol:phosphatidylserine $=13.3: 13.3: 13.3: 50: 10$ in molar ratio) was dried by reversedphase evaporation. The dried lipid was then hydrated in $200 \mu \mathrm{L}$ of balanced salt solution $(\mathrm{BSS}=137 \mathrm{mmol} / \mathrm{L} \mathrm{NaCl} / 5.4 \mathrm{mmol} / \mathrm{L}$ $\mathrm{KCl} / 10 \mathrm{mmol} / \mathrm{L}$ Tris $\mathrm{HCl}, \mathrm{pH}$ 7.6). The PGIS expression plasmid (200 $\mu \mathrm{g}$ in $200 \mu \mathrm{L}$ BSS) or $200 \mu \mathrm{L}$ BSS alone (control vector) was added. Liposomes were prepared by shaking and sonication. Purified HVJ ( $Z$ strain) was inactivated by ultraviolet irradiation (110 ergs $\cdot \mathrm{mm}^{-2} \cdot \mathrm{s}^{-1}$ ) for 3 minutes just before use. The liposome 
suspension $(0.5 \mathrm{~mL}$, containing $10 \mathrm{mg}$ of lipids) was mixed with HVJ (15,000 hemagglutinating units) in a total volume of $4 \mathrm{~mL}$ of BSS. The mixture was incubated at $4{ }^{\circ} \mathrm{C}$ for 5 minutes and then for 60 minutes with gentle shaking at $37^{\circ} \mathrm{C}$. Free $\mathrm{HVJ}$ was removed from the HVJ liposomes by sucrose density gradient centrifugation. The top layer of the sucrose gradient, which contained the HVJ liposomes, was collected. The HVJ liposomes were then collected as a pellet by centrifugation at $19,350 \mathrm{~g}$ at $4^{\circ} \mathrm{C}$ for 30 minutes and resuspended in $2 \mathrm{~mL}$ of BSS before use. This HVJliposome solution was used for gene transfer with the addition of $\mathrm{CaCl}_{2}$ (final concentration, $1 \mathrm{mmol} / \mathrm{L}$ ). This preparation method has been optimized to achieve maximal transfection efficiency, as reported previously.

\section{Enzyme Immunoassays for 6-Keto-prostaglandin $\mathbf{F}_{1 \alpha}$, Total Collagen, and Endothelin-1, and Bicinchoninic Acid Assay for Protein}

The level of 6-keto-prostaglandin $\mathrm{F}_{1 \alpha}$, a stable hydrolyzed metabolite of prostacyclin, was analyzed with an enzyme immunoassay kit (Assay Designs, Inc, Ann Arbor, Mich). The levels of total collagen in lung tissue were analyzed with a Sircol collagen assay kit (Biocolor Assays; Biocolor Ltd, Belfast, Northern Ireland). The levels of endothelin-1 in lung tissues were analyzed with an endothelin-1 EIA kit (Cayman Chemical Company, Ann Arbor, Mich). Protein levels of the same tissues as those used for the total collagen assays were measured with a bicinchoninic acid protein assay kit (Pierce Chemical Company, Rockford, Ill). The amount of total collagen or endothelin-1 in tissue is presented as a ratio to the amount of total protein. All assays were carried out as described by the manufacturers.

\section{Immunohistological Analysis}

Seven days after the transfer of PGIS expression plasmid or control vector, the lungs and livers of the MCT rats were stained immunohistochemically with a rabbit polyclonal antibody raised against a partial sequence of the human PGIS sequence. Twomicron-thick sections of paraffin-embedded tissues were prepared, then de-paraffinized before staining. The sections were incubated in $3 \%$ hydrogen peroxide for 30 minutes to block endogenous peroxidase activity and to permeabilize the cells. Nonspecific binding of rabbit serum was prevented by preincubating the sections with $0.2 \%$ normal goat serum. The sections were incubated at $4^{\circ} \mathrm{C}$ with rabbit antibody against human PGIS at a concentration of 1:1000 overnight and then with biotinylated goat anti-rabbit immunoglobulin G (Dako Japan Co Ltd, Kyoto, Japan) for $30 \mathrm{~min}-$ utes, followed by peroxidase labeling with streptavidin (LSAB kit; Dako Japan Co) for an additional 20 minutes at room temperature. Each incubation was followed by washing in phosphate-buffered saline solution with Tween 20. Staining was visualized with a chromogen, $0.06 \% 3,3^{\prime}$-diaminobenzidine $/ 0.03 \%$ hydrogen peroxide in $8 \mathrm{mmol} / \mathrm{L}$ Tris- $\mathrm{HCl}(\mathrm{pH}$ 6.85). Hematoxylin was used as a counterstain. Control sections were incubated with nonimmune rabbit immunoglobulin $\mathrm{G}$ at a concentration of 1:1000.

\section{Western Blotting Analysis}

Frozen tissues were homogenized with a Thyristor Regler TR50 (Janke \& Kunkel IKA-WERK, Staufen, Germany) with RIPA buffer (phosphate-buffered saline solution, 1\% nonionic detergent
P-40, $0.5 \%$ sodium deoxycholate, $0.1 \%$ sodium lauryl sulfate, 1.1 $\mathrm{mmol} / \mathrm{L}$ phenylmethylsulfonyl fluoride, and $5 \mathrm{ng} / \mathrm{mL}$ leupeptin). The homogenized tissues were spun $(200 g$, 20 minutes, Kubota 2010 centrifuge; ITS Science \& Medical Pte Ltd, Singapore), and the protein concentration of the supernatants was measured with a bicinchoninic acid protein assay kit. Samples containing a similar amount of total protein were combined with 5- $\mu$ L RIPA buffer, $10-\mu \mathrm{L}$ sodium dodecylsulfate sample buffer (BioLabs Co, Singapore), and 1- $\mu \mathrm{L} \beta$-mercaptoethanol (Wako, Japan), and were incubated at $90^{\circ} \mathrm{C}$ for 5 minutes. The protein extracts were separated on a $10 \%$ to $20 \%$ denaturing polyacrylamide gradient gel (Multigel; Daiichi Pure Chemicals Co, Ltd, Tokyo, Japan), then electrophoretically transferred to a Hybond-PVDF membrane (ASSO Co). The membrane was blocked with $5 \%$ nonfat dry milk in Tris-buffered saline solution containing $0.1 \%$ Tween-20. After blocking, the membrane was incubated at room temperature with the appropriate dilution of the rabbit polyclonal antibody $(1: 1000)$, washed with triethanolamine-buffered saline solution containing $0.1 \%$ Tween-20, then incubated with a goat anti-rabbit immunoglobulin G-horseradish peroxidase conjugate. After washing, chemiluminescence was used to detect the protein bands (ECL kit; Amersham Corp, Arlington Heights, Ill).

\section{Statistical Analysis}

All data are expressed as means \pm SEM unless otherwise indicated. Parameters between the two groups were analyzed by an unpaired Student $t$ test. Survival curves between the two groups were derived by means of the Kaplan-Meier method and compared by log-rank tests.

\section{Results \\ RV/FA Pressure Ratio}

The RV/FA ratios and the RV/FA pressures after injection of PGIS-HVJ liposomes or HVJ liposomes (without plasmid) are presented in Figure 2. After gene transfection, the $\mathrm{RV} / \mathrm{FA}$ pressure ratio decreased from approximately 1 to 0.596 in the PGIS group and from 1 to 0.879 in the control group. The decrease in the RV/FA ratio was significantly greater in the PGIS group than that in the control group (PGIS vs control, $0.596 \pm 0.039$ vs $0.879 \pm 0.051 ; P=$ .0036).

\section{6-Keto-Prostaglandin $\mathrm{F}_{1 \alpha}$ Analysis}

The results of blood analysis are shown in Figure 3. The PGIS group showed significantly higher plasma levels of 6-keto-prostaglandin $\mathrm{F}_{1 \alpha}$ than did the control group (PGIS vs control, $35.43 \pm 4.42 \mathrm{ng} / \mathrm{mL}$ vs $22.34 \pm 3.33 \mathrm{ng} / \mathrm{mL}$; $P=.0436)$

\section{Immunohistochemical Staining}

The results of the immunohistologic analysis are presented in Figure 4. The hepatic cells showed strong positive staining for PGIS only in the PGIS group. The PGIS-positive cells were mainly located around the hepatic central veins. In contrast, no or very little immunoreactivity was observed in the control livers. No positive cells were observed in the lungs of either group. 

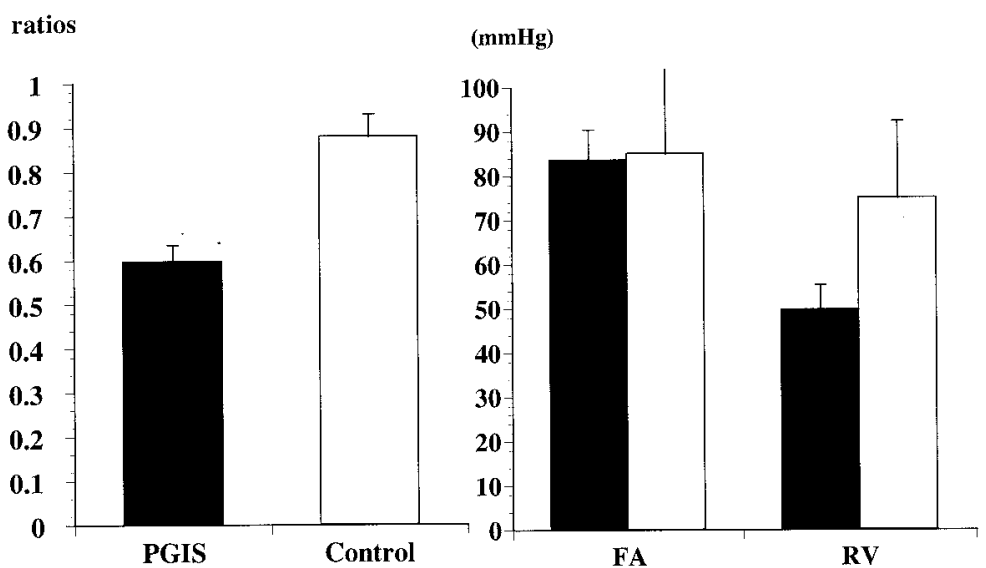

Figure 2. After the injection of PGIS cDNA, the RV/FA pressure ratios decreased significantly in the PGIS group compared with the control group (PGIS vs control, $0.596 \pm 0.039$ vs $0.879 \pm 0.051 ; P=.0036$ ). There were no significant differences in the femoral arterial pressures between the two groups (PGIS vs control, $83.6 \pm 6.9 \mathrm{~mm}$ Hg vs $85.0 \pm 19.7 \mathrm{~mm} \mathrm{Hg;} P=.937)$.

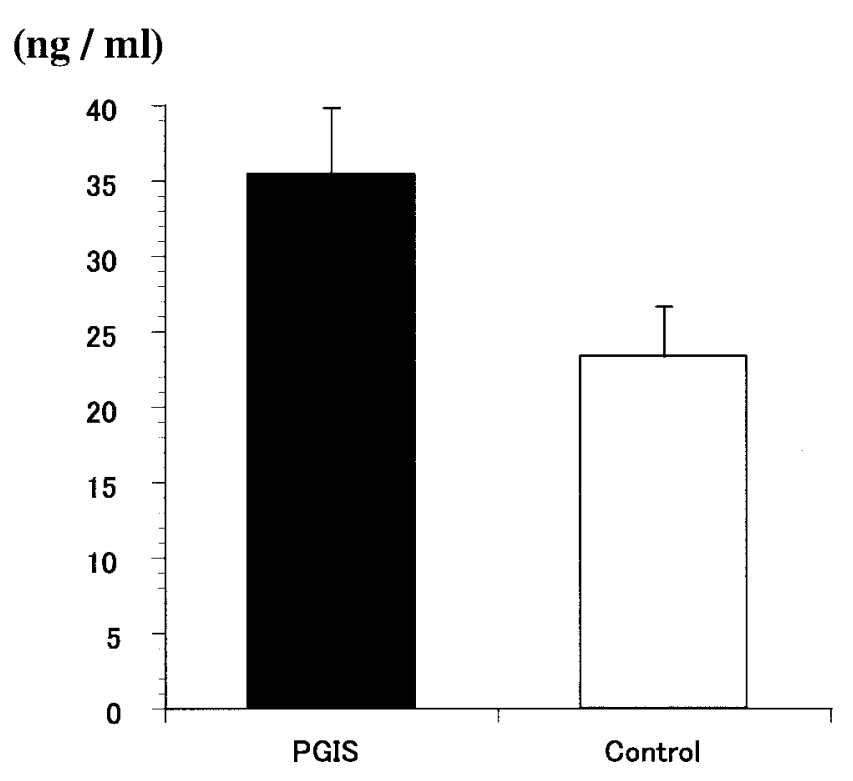

Figure 3. The plasma levels of 6 keto-PG $F_{1 \alpha}$ in the PGIS genetransfected group were significantly higher than in the control group (PGIS vs control, $35.43 \pm 4.42 \mathrm{pg} / \mathrm{mL}$ vs $23.34 \pm 3.33 \mathrm{pg} / \mathrm{mL}$; $P=$.0436).

\section{Western Blot Analysis}

The results of Western blotting are presented in Figure 5. PGIS was expressed predominantly as a single band at approximately $56 \mathrm{kD}$ in the PGIS and control groups. However, PGIS was expressed at a significantly higher level in the PGIS group than in the control group. In contrast, PGIS expression was not detected in the lungs of either group (lanes 3 and 4).

\section{Collagen and Endothelin-1 in Lung}

The concentration of endothelin- 1 in the lung tissue was significantly lower in the PGIS group than in the control group (PGIS vs control, $10.42 \pm 2.01 \mathrm{pg} / \mathrm{mg}$ protein vs $19.94 \pm 2.82 \mathrm{pg} / \mathrm{mg}$ protein; $P=.0176$ ) (Figure 6, A).The collagen concentration in the lung was compared between the PGIS and control groups. The amount of total collagen in the lung was less in the PGIS group than in the control group, although the difference was not statistically significant (PGIS vs control, $0.75 \pm 0.11 \mu \mathrm{g} / \mathrm{mg}$ protein vs $1.05 \pm$ $0.21 \mu \mathrm{g} / \mathrm{mg}$ protein; $P=.192$ ) (Figure $6, B$ ).

\section{Survival Ratio Analysis After PGIS Transfection}

Survival curves generated by Kaplan-Meier analysis are presented in Figure 7. The cumulative survival ratios were 0.511 for the PGIS group and 0.107 for the control group 60 days after MCT injection. The survival ratio was significantly higher for the PGIS group than for the control group $(P=.0375)$.

\section{Discussion}

In this study, we demonstrated that transfer of the human PGIS gene into the liver increased the prostacyclin level, resulting in the amelioration of MCT-induced pulmonary hypertension. Moreover, PGIS-transfected MCT rats showed higher survival than the MCT rats that did not receive the transgene. The PGIS-transfected group showed significantly lower level of endothelin-1, a marker for lung remodeling, in the lung. These data suggest that transfection of the PGIS gene to the liver resulted in a drug delivery system of prostacyclin for the lung, and therefore this may be an effective treatment for pulmonary hypertension.

The conventional treatments for pulmonary hypertension include calcium blockers, phosphodiesterase inhibitors, and 

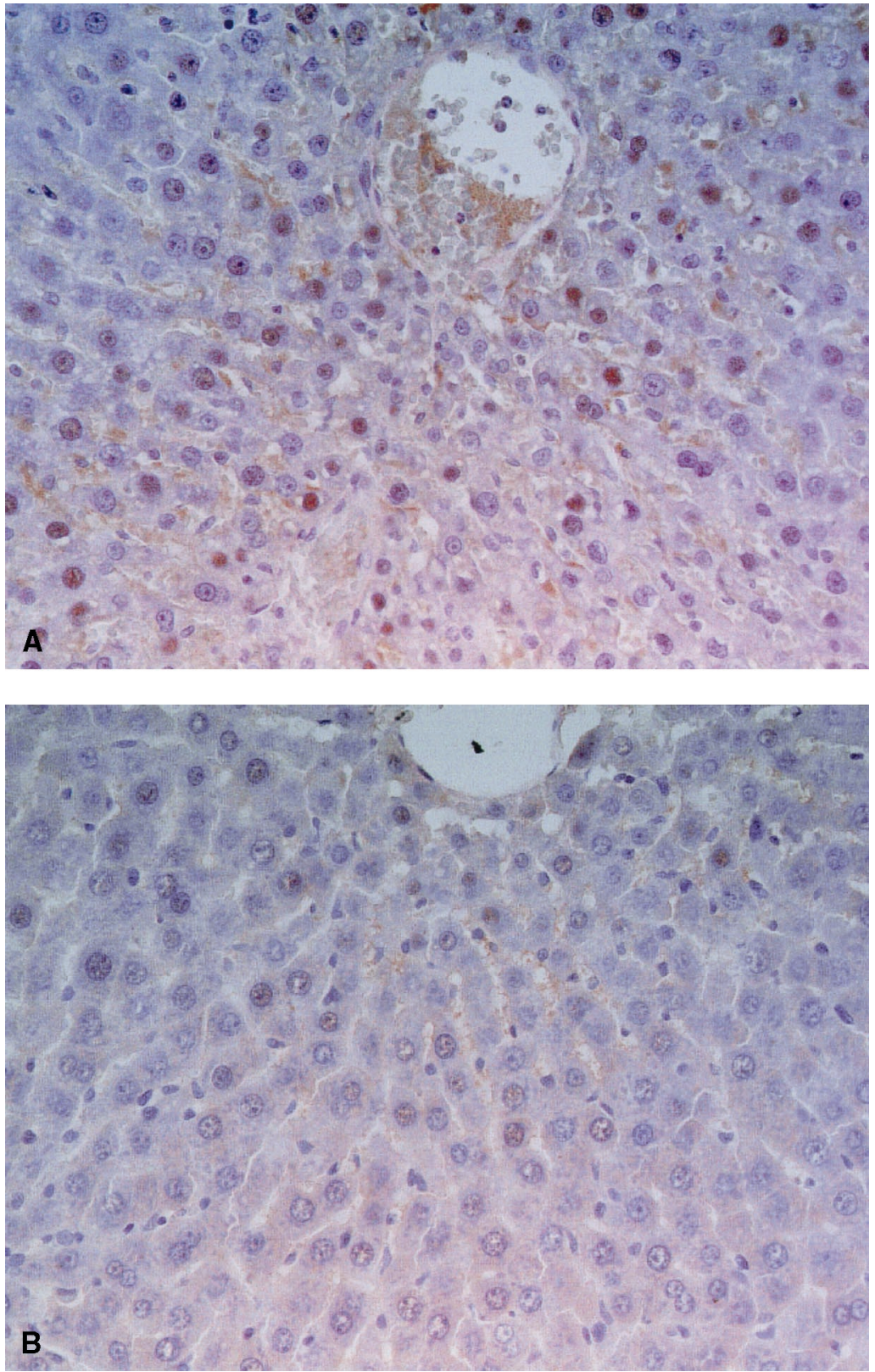

Figure 4. Immunohistochemical staining was performed with an anti-human prostaglandin $\mathrm{I}_{2}$ synthase antibody. Immuno-positive cells were found around central veins in the PGIS group (A) but not in the control group (B). No positive cells were found in the lung in either the PGIS or control group. (Original magnification $\times 400$.)

inhaled nitric oxide. ${ }^{16}$ Although aerosolized prostacyclin has been suggested for selective pulmonary vasodilation, similar to inhaled nitric oxide, its effect rapidly drops after the nebulization treatment. ${ }^{17}$ The long-term continuous intravenous administration of prostacyclin analogs has also been reported to be effective for primary and secondary pulmonary hypertension, ${ }^{2-4}$ but it is difficult to continue such therapy in a clinical setting. As a general pharmacologic principle to treat pulmonary hypertension, combina- tions that produce similar effects via different mechanisms, such as inhaled nitric oxide, calcium blockers, phosphodiesterase inhibitors, and prostacyclin analogs, appear to have additive or synergistic effects. However, such combination therapy is still limited in its effectiveness over the long term.

Increasing the production of intrinsic prostacyclin as a drug delivery system seems to be useful. For example, Geraci and colleagues ${ }^{18}$ reported that overexpression of PGIS in the lungs of transgenic mice attenuated the devel- 


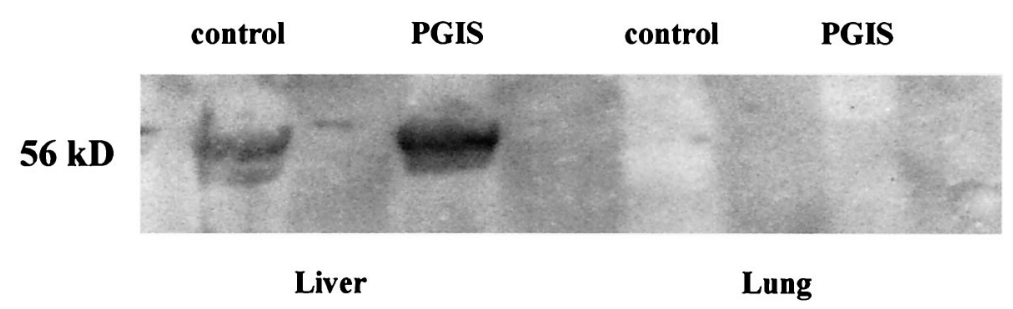

Figure 5. Western blotting was performed with an anti-human prostaglandin $\mathrm{I}_{2}$ synthase antibody. First lane, Control (liver); second lane, PGIS (liver); third lane, control (lung); fourth lane, PGIS (lung). Overexpression of prostaglandin $\mathrm{I}_{2}$ synthase protein in the transfected liver of the PGIS group was confirmed (56-kD band). However, the expression of PGIS protein in the lung was not found for the PGIS group.
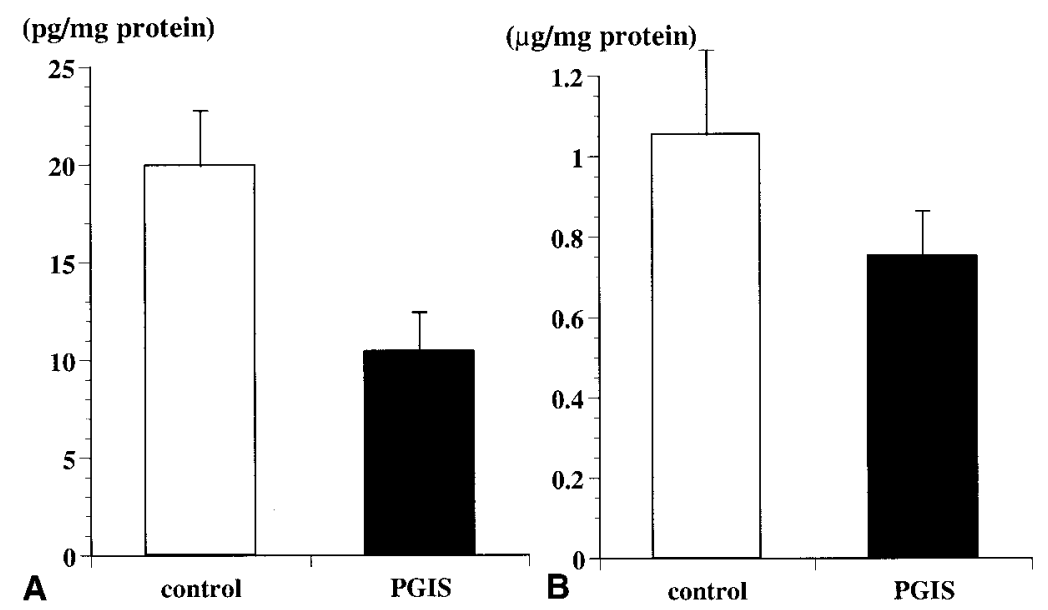

Figure 6. A, The levels of endothelin-1 in lung tissue were determined. PGIS versus control, $10.42 \pm 2.01 \mathrm{pg} / \mathrm{mg}$ protein versus $19.94 \pm 2.82 \mathrm{pg} / \mathrm{mg}$ protein. B, The amount of total collagen in lung tissue was determined. PGIS versus control, $0.75 \pm 0.11 \mu \mathrm{g} / \mathrm{mg}$ protein versus $1.05 \pm 0.21 \mu \mathrm{g} / \mathrm{mg}$ protein; $P=.192$ ).

ratio

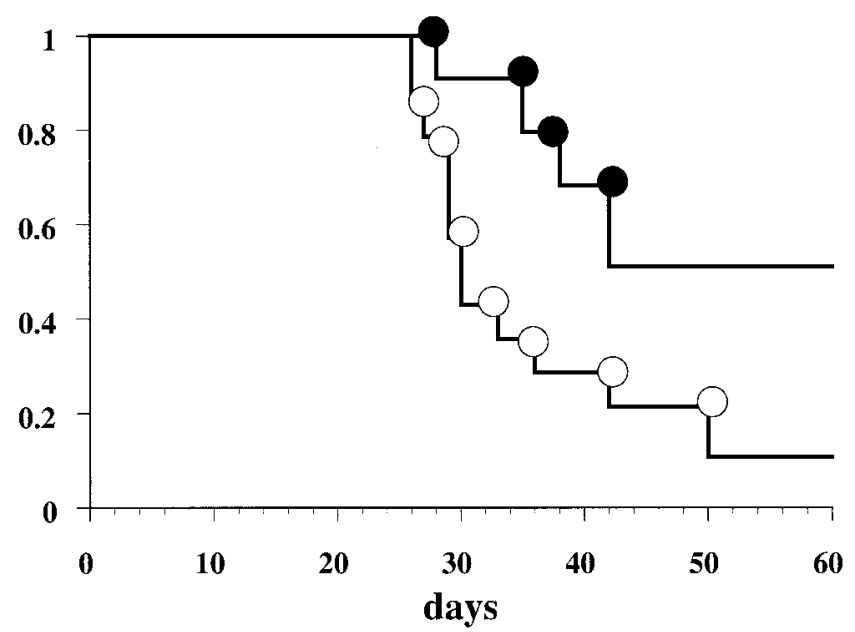

Figure 7. Survival ratios were analyzed by the Kaplan-Meier method. The survival ratios were significantly higher in the PGIS group than in the control group (log-rank test, $P=.0375$ ). opment of hypoxic pulmonary hypertension. On the other hand, we thought that gene transfer of PGIS would be useful in clinical settings and that gene transfection into the liver as a drug delivery organ would enable stable and less-invasive treatments for pulmonary hypertension.

Intratracheal inhalation methods have also been reported to be useful for gene transfection to the lungs. ${ }^{11,19}$ Although this method appears to be convenient for clinical application, it has limitations, such as limited areas of transfection in the lung and low efficiency of transfection into endothelial cells, and it causes deterioration of respiratory function, especially in critically ill patients. ${ }^{20,21}$ Moreover, aerosolized plasmid-vector complexes in the air expelled by the patients can introduce undesirable pollutants into the air, where they can be inhaled by others.

In contrast, transfection of PGIS to the liver avoids these problems. Here, we showed prostacyclin from PGIS transfected into the liver could be delivered to the pulmonary artery via hepatic veins, the inferior vena cava, right atrium, and right ventricle as a drug delivery system for the lung. It 
appears that gene transfection via such a hepatic approach could be performed safely in clinical settings, even in patients with poor respiratory function. In our study, none of the rats showed any adverse effects from the treatment, including low blood pressure and liver dysfunction. Although further investigations are needed, hepatic delivery system of prostacyclin with PGIS seems to be a potentially useful application of gene therapy.

The efficient intratracheal transfer of the human PGIS gene at the same time as MCT injection was previously reported to prevent the progression of the MCT-induced pulmonary hypertension in rats. ${ }^{11}$ However, it has not yet been determined whether the PGIS gene transfection by intratracheal inhalation was efficient enough to ameliorate advanced pulmonary hypertension in the chronic phase. In our study, a high pulmonary arterial pressure equal to the systemic arterial pressure was significantly decreased by PGIS gene transfection during the chronic phase of MCTinduced pulmonary hypertension. Although no morphologic changes were detected in the pulmonary vessels, decreases in endothelin-1 in the lung tissue were detected 7 days after PGIS gene transfection. It may demonstrate that PGIS gene transfection also indirectly affects the biologic responses via cyclic guanosine monophosphate receptors, on which endothelin and nitric oxide act. The concentration of total collagen in the lung showed a slightly lower level in the PGIS group. A longer follow-up is required to confirm whether PGIS transfection improves the regeneration of lung tissues in advanced pulmonary hypertension.

In the clinical setting, percutaneous liver injection, such as percutaneous ethanol injection therapy, has been performed in general surgery with ultrasonography as a treatment for hepatoma. Therefore, the percutaneous injection of genes into the liver may be performed safely and effectively by such techniques. However, Brigham and Stecenko ${ }^{21}$ pointed out that gene therapy for a treatment of lung diseases has not yet been adopted clinically, as had been expected. They indicated that the reason was difficulty in coping with both its safety and efficacy as for the viral or nonviral vectors and delivery systems. ${ }^{21}$ Although HVJ liposome was used as a transfection method in this study, its durability of transfection may have limitations the same as adenovirus vector or the liposome method. In addition, the side effects associated with the increased prostaglandin $\mathrm{I}_{2}$ levels are still unknown. Further study, including the search for better vectors and delivery technologies, is needed to optimize the conditions for PGIS gene transfer to prolong the overexpression of PGIS with minimal or no side effects.

In conclusion, gene transfer of human prostacyclin synthase into the liver may be an alternative for the treatment of pulmonary hypertension in the future.

We thank Akiko Nishimura and Shigeru Matsumi for their technical assistance.

\section{References}

1. Barst RJ. Pharmacologically induced pulmonary vasodilation in children and young adults with primary pulmonary hypertension. Chest. 1986;89:497-503.

2. Rosenzweig EB, Kerstein D, Barst RJ. Long-term prostacyclin for pulmonary hypertension with associated congenital heart defects. Circulation. 1999;99:1858-65.

3. Barst RJ, Maislin G, Fishman AP. Vasodilator therapy for primary pulmonary hypertension in children. Circulation. 1999;99:1197-208.

4. Langleben D, Barst RJ, Badesch D, Groves BM, Tapson VF, Murali $\mathrm{S}$, et al. Continuous infusion of epoprostenol improves the net balance between pulmonary endothelin-1 clearance and release in primary pulmonary hypertension. Circulation. 1999;99:3266-71.

5. Moncada S, Vane JR. Arachidonic acid metabolites and the interactions between platelets and blood-vessel walls. N Engl J Med. 1979; 300:1142-7.

6. Hara S, Miyata A, Yokoyama C, Inoue H, Brugger R, Lottspeich F, et al. Isolation and molecular cloning of prostacyclin synthase from bovine endothelial cells. J Biol Chem. 1994;269:19897-903.

7. Miyata A, Hara S, Yokoyama C, Inoue H, Ullrich V, Tanabe $T$. Molecular cloning and expression of human prostacyclin synthase. Biochem Biophys Res. 1994;200:1728-34.

8. Tone Y, Inoue H, Hara S, Yokoyama C, Hatae T, Oida H, et al. The regional distribution and cellular localization of mRNA encoding rat prostacyclin synthase. Eur J Cell Biol. 1997;72:268-77.

9. Hara S, Morishita R, Tone Y, Yokoyama C, Inoue H, Kaneda Y, et al. Overexpression of prostacyclin synthase inhibits growth of vascular smooth muscle cells. Biochem Biophys Res Commun. 1995;216:862-7.

10. Tokada T, Yokoyama C, Yamamoto H, Hashimoto N, Nagata I, Tsukahara $\mathrm{T}$, et al. Gene transfer of human prostacyclin synthase prevents neointimal formation after carotid balloon injury in rats. Stroke. 1999;30:419-26.

11. Nagaya N, Yokoyama C, Kyotani S, Shimonishi M, Morishita R, Uematsu M, et al. Gene transfer of human prostacyclin synthase ameliorates monocrotaline-induced pulmonary hypertension in rats. Circulation. 2000;102:2005-10.

12. Kolodka, TM, Finegold M, Moss L, Woo SL. Gene therapy for diabetes mellitus in rats by hepatic expression of insulin. Proc Natl Acad Sci U S A. 1995;92:3293-7.

13. Muzzin P, Eisensmith RC, Copeland KC, Woo SL. Hepatic insulin gene expression as treatment for type 1 diabetes mellitus in rats. $\mathrm{Mol}$ Endocrinol. 1997;11:833-7.

14. Mitanchez D, Chen R, Massias JF, Porteu A, Mignon A, Bertagna X, et al. Regulated expression of mature human insulin in the liver of transgenic mice. FEBS Lett. 1998;421:285-9.

15. Saeki Y, Matsumoto N, Nakano Y, Mori M, Awai K, Kaneda Y. Development and characterization of cationic liposomes conjugated with HVJ (Sendai virus): reciprocal effect of cationic lipid for in vitro and in vivo gene transfer. Hum Gene Ther. 1997;8:2133-41.

16. Schermuly RT, Roehl A, Weissmann N, Ghofrani HA, Schudt C, Tenor H, et al. Subthreshold doses of specific phosphodiesterase type 3 and 4 inhibitors enhance the pulmonary vasodilatory response to nebulized prostacyclin with improvement in gas exchange. J Pharmacol Exp Ther. 2000;292:512-20.

17. Hill LL, Pearl RG. Combined inhaled nitric oxide and inhaled prostacyclin during experimental chronic pulmonary hypertension. J Appl Physiol. 1999;86:1160-4.

18. Geraci MW, Gao B, Shepherd DC, Moore MD, Westcott JY, Fagan $\mathrm{KA}$, et al. Pulmonary prostacyclin synthase overexpression in transgenic mice protects against development of hypoxic pulmonary hypertension. J Clin Invest. 1999;103:1509-15.

19. Champion HC, Bivalacqua TJ, Toyoda K, Heistad DD, Hyman AL, Kadowitz PJ. In vivo gene transfer of prepro-calcitonin gene-related peptide to the lung attenuates chronic hypoxia-induced pulmonary hypertension in the mouse. Circulation. 2000;101:923-30.

20. Takeda S, Miyoshi S, Omori K, Utsumi T, Kogaki S, Sawa Y. Pulmonary disease models induced by in vivo hemagglutinating virus of Japan liposome-mediated endothelin-1 gene transfer. J Cardiovasc Pharmacol. 1998;31(Suppl 1):336-8.

21. Brigham KL, Stecenko AA. Gene therapy for acute lung injury. Intensive Care Med. 2000;26:S119-23. 